\title{
Ciências e matemática do sol e do gnômon $\left.\right|^{1}$
}

\author{
Science and mathematics of the sun and gnomon
}

José Antonio Salvador ${ }^{2}$

\section{Resumo.}

Neste trabalho buscamos direcionar o processo de ensino-aprendizado de alguns conceitos matemáticos básicos por meio de observações simples do mundo em que vivemos. Por exemplo, as observações que foram feitas antes mesmo de Galileu, que apontou o primeiro telescópio para o céu há mais de 400 anos, inaugurando uma nova era na ciência. Algumas delas, como as investigações da projeção da sombra solar de um gnômon, experiências de observação da direção e tamanho da sombra para determinar o meridiano local, a construção da rosa dos ventos, medição de alturas e tamanhos de objetos inacessíveis, da circunferência da Terra, construção de relógios de sol, etc. pode motivar professores e estudantes a entender os movimentos da Terra e a importância do Sol e do seu carater multidisciplinar, gerando gosto nos estudantes pelas descobertas da ciência e da matemática. A reprodução desses experimentos pode contribuir para o aprendizado de medidas, ângulos, distâncias, bissetrizes, paralelismo, perpendicularismo, circunferência, triângulo, semelhança, regra de três, trigonometria, etc. A nossa proposta está alinhada com as competências, habilidades e eixos norteadores apontados pela Base Nacional Comum Curricular sugerindo a articulação entre as áreas do conhecimento, no que tange à representação, comunicação, pesquisa, entendimento e contexto sociocultural.

Palavras - chave. Ensino de ciências e matemática, orientação, gnômon, relógios de sol.

\begin{abstract}
.
In this work we seek to stimulate the teaching - learning process of some basic mathematical concepts through simple observations of the world we live in. For instance those that were made even before Galileo, who aimed the first telescope at the sky more than 400 years ago and ushered in a new era for science. Experiments such as investigating the projection of the
\end{abstract}

\footnotetext{
${ }^{1}$ Trabalho apresentado na IV Semana de Matemática \& III Workshop de GeoGebra do Pontal, 2013.

${ }^{2}$ Departamento de Matemática, Universidade Federal de São Carlos, salvador@dm.ufscar.br
} 
solar shadow of a gnomon, observing the direction and size of the shadow to determine the local meridian, construction of the wind rose, measurement of heights and sizes of inaccessible objects, measurement of the circumference of the earth, construction of sundials, etc. The reproduction of these experiments can motivate both teachers and students to adquire the understanding of the Earth's movements and the importance of the Sun, and its multidisciplinary character, generating a taste for the discoveries of science and mathematics. The execution of such experiments can contribute to the learning of measures, angles, distances, bisectors, parallelism, perpendicularity, circumference, triangle, similarity, rule of three, trigonometry, etc. Our purpose is in line with the skills, competences and guiding axes touted by the National Common Curricular Base as possibilities of articulation between the areas of knowledge, regarding representation, communication, research, understanding and sociocultural context.

Keywords. Science and mathematics teaching, orientation, gnomon, sundials.

\section{Introdução}

Os questionamentos sobre o universo remontam aos tempos pré - históricos. E hoje ao perguntarmos aos nossos estudantes onde o sol nasce, a resposta comum que obtemos é que o sol nasce no leste. Mas, quando é que isso realmente acontece? Será que o sol nasce sempre no mesmo local? $\mathrm{O}$ sol nasce todo dia à mesma hora onde você mora? $\mathrm{O}$ sol fica a pino na sua região? O sol sempre fica a pino ao meio - dia? Em que dia(s) do ano o sol fica a pino ao meio - dia? Em que lugar(es) da superfície terrestre é possível ver o sol a pino ao meio - dia? E a sombra de um objeto muda de direção e de tamanho durante o dia? Durante os vários dias do ano a projeção da sombra mínima da ponta de um gnômon (uma haste fincada verticalmente no solo) varia de tamanho? Será que o sol nasce no mesmo local no início das estações do ano? E o pôr do sol é sempre no mesmo local? Como podemos nos orientar e nos localizarmos? Em que direção fica a frente da sua casa? E da sua escola? Como orientar a construção de uma casa ou de uma escola de modo que ela receba a máxima iluminação natural? Como inclinar o telhado de uma construção para colocação de placas solares, visando otimizar a energia recebida, especialmente nos meses de inverno? como medir as horas durante o dia?

A BNCC (BRASIl [2], Base Nacional Comum Curricular, aponta para garantirmos que os estudantes relacionem observações empíricas do mundo real a representações (tabelas, figuras e esquemas) e associem essas representações a uma atividade matemática (conceitos e propriedades), fazendo induções e conjecturas. Os problemas sugeridos aqui 
e outros relacionados, vão neste sentido e podem despertar o interesse nos estudantes de ensino básico para as Ciências e Matemática e fazer com que eles fixem os conteúdos naturalmente. O docente poderá escolher o momento e o ano escolar conveniente para abordá-los com a devida profundidade que desejar, uma vez que a geração de hoje tem a tecnologia disponível e é capaz de uma aprendizagem não necessariamente linear dos conteúdos.

Desde criança percebemos que o movimento dos mourões de uma cerca fixos nas margens de uma estrada vão ficando para trás quando viajamos sentados no banco de um veículo. O movimento aparente deles é no sentido contrário ao movimento do veículo. Da mesma maneira como nossos antepassados, observamos o movimento circular aparente de toda a esfera celeste de leste para oeste todos os dias. Em particular, o sol nasce de um lado no horizonte e, elevando-se, ilumina e aquece a Terra à medida que vai alcançando um ponto mais alto no céu e depois vai descendo até desaparecer completamente, se pondo do outro lado completando um arco de circunferência. Chega a noite, vêm as estrelas, que percorrem o céu, num caminho aparentemente no mesmo sentido do Sol, cada uma decrevendo seu próprio arco de circunferência.

Hoje, sabemos que a Terra tem um movimento diário de rotação ao redor de seu próprio eixo, de oeste para leste, e de translação anual ao redor do Sol durante aproximadamente 365,25 dias, com uma velocidade cerca de $30000 \mathrm{~m} / \mathrm{s}$, além de outros movimentos menos notórios como os de precessão, nutação e do deslocamento do periélio, conforme OLIVEIRA FILHO \& SARAIVA [9].

Ao observar diariamente o aparecimento do Sol nas manhãs, através de uma fresta na porta ou janela de nossa casa, durante um intervalo de algumas semanas, percebemos que ele não nasce no mesmo local todos os dias. E, então, onde fica o Leste (o oriente) verdadeiro? Algumas dessas questões serão discutidas nas próximas seções ou propostas como atividades interdisciplinares diferenciadas para o processo de ensino aprendizagem significativo.

\section{Orientar é procurar o oriente}

A necessidade de contagem do tempo e de orientação na superfície terrestre ou no mar se intensificou com o surgimento dos deslocamentos dos povos e das grandes navegações tornando-se indispensável para o homem. Uma das primeiras divisões do tempo que fizemos foi a do dia e noite. As primeiras noções para nos orientarmos é considerarmos um referencial, por exemplo, os objetos fixos ao nosso redor e a observação dos astros no céu.

As primeiras civilizações observaram certas regularidades e padrões no céu, como a 
posição da estrela Polar na cauda da constelação da Ursa Menor, que está praticamente fixa na direção do polo norte celeste, prolongamento do polo norte terrestre, conforme podemos simular no Stellarium [13]. As estrelas circunvizinhas da estrela Polar parecem descrever uma circunferência completa ao seu redor durante um dia, em que a sua projeção no horizonte indica a direção norte e orienta os povos daquele hemisfério.

Os povos do sul e os primeiros navegantes que se aventuraram para cá consideravam a constelação do Cruzeiro do Sul uma boa referência para determinar o polo sul, já que a $\sigma$ do oitante, estrela mais próxima do polo sul celeste é de magnitude 5,4 quase invisível a olho nú. De fato, tomando como referência o braço maior do Cruzeiro, formado por um arco de $6^{\circ}$ (seis graus) unindo a estrela $\alpha$ (Magalhães), a mais brilhante que se encontra no pé do Cruzeiro e representa o estado de São Paulo na bandeira brasileira, e a estrela $\gamma$ (Rubídea), na cabeça do Cruzeiro, e prolongando aproximadamente quatro vezes e meia, obtemos um ponto na esfera celeste, o polo sul celeste, que projetado no horizonte, nos dá a direção sul conforme a Figura 1,

Com a descoberta da propriedade diretiva do ímã se construiu a Bússola, um instrumento de orientação composto de uma agulha magnética na horizontal, suspensa pelo centro de gravidade, apontando para a direção N - S (Norte - Sul) magnética. Embora não coincida exatamente com o Polo Norte geográfico ela nos fornece uma orientação aproximada para a maioria dos pontos da superfície terrestre.

A localização do polo sul celeste pelo Cruzeiro do Sul durante uma noite estrelada pode ser imprecisa, entretanto, é possível determinar a direção $\mathrm{N}$ - S fazendo uma simples experiência da projeção da sombra de um gnômon durante um dia ensolarado, e em várias épocas do ano como nos solstícios e equinócios. A posição do sol pela manhã e tarde é importante, não só pela luz, calor, energia e vida que ele fornece para nossa sobrevivência na Terra, mas para nos orientarmos geograficamente com certa precisão. Observamos que a trajetória aparente do sol na esfera celeste durante um dia ensolarado é um arco de circunferência em torno do eixo terrestre, e faz com que a direção da sombra de um gnômon varie de posição e de tamanho. Durante o ano todo, podemos observar o tamanho mínimo da sombra de um gnômon ao longo dos dias ensolarados como na Figura 2 .

O segmento de reta da sombra mínima do gnômon (vertical), num dia ensolarado, está contido no meridiano local, mostrando a direção N - S. A linha perpendicular ao meridiano local nos dá a direção L - O (Leste - Oeste) verdadeira. É fácil observar que os tamanhos das sombras de um gnômon ao longo do dia vão diminuindo da manhã até o meio - dia solar verdadeiro, quando o sol atinge o ponto mais alto no céu cruzando o meridiano celeste local, e depois, vai aumentando à medida que vai entardecendo.

A linha meridiana local também pode ser obtida marcando a direção da bissetriz das sombras da manhã e da tarde de mesmo tamanho de um gnômon, especialmente num dia 


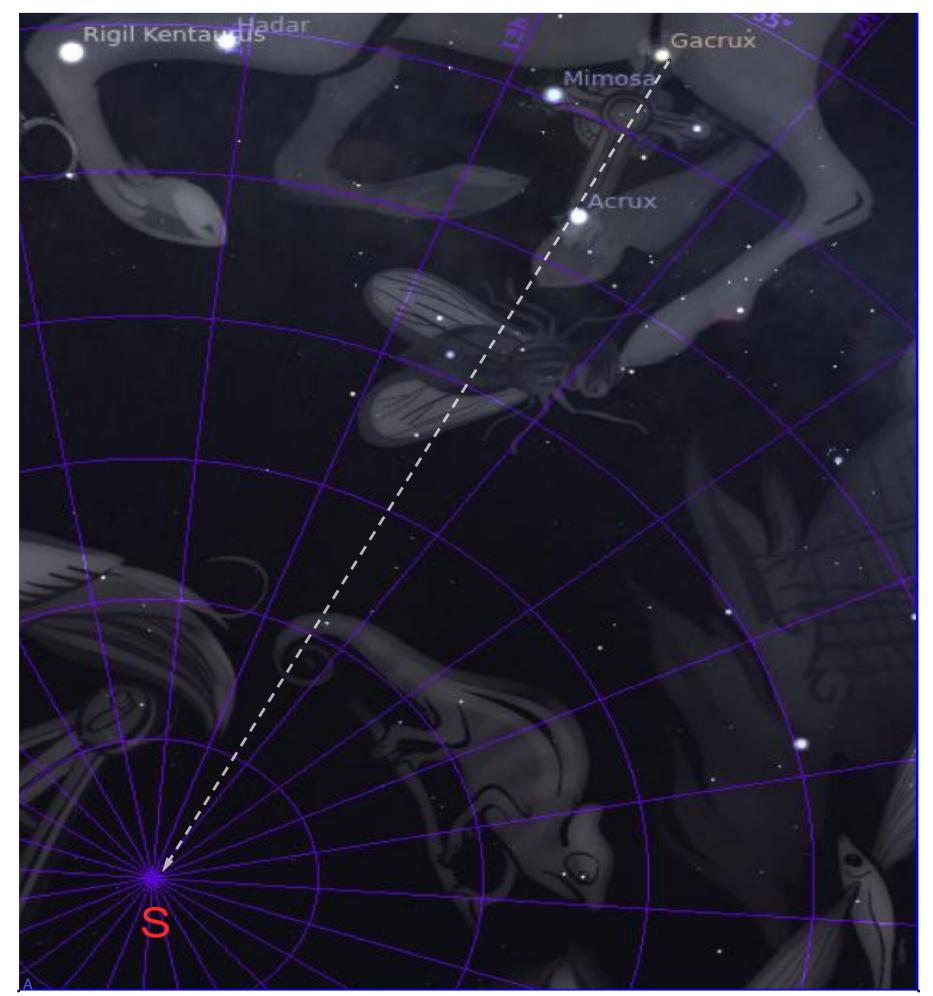

Figura 1: A orientação pelo braço maior do Cruzeiro do Sul. Fonte: Adaptado de imagem do Stellarium pelo autor.

de equinócio para quem vive entre os trópicos, em que a sombra mínima é nula, pois o sol passa pelo zênite do observador exatamente ao meio - dia solar verdadeiro conforme SALVADOR [12].

O procedimento deste simples experimento consiste em fincar um gnômon num local onde se tenha sol de manhã e de tarde, pelo menos próximo do meio - dia solar verdadeiro. Usa-se um fio de prumo para certificar-se de que gnômon está realmente na posição vertical, perpendicular ao plano do horizonte local e, consequentemente, apontando para o centro da Terra. Traçamos no chão dois ou mais arcos de circunferências de sombra concêntricos das extremidades da sombra do gnômon $G$, usando, por exemplo, um pedaço de barbante amarrado no pé do gnômon. Marcamos neles os raios de sombra da manhã, por exemplo, $s_{1}$ e $s_{3}$, ligando os pontos extremos das sombras no pé do gnômon, conforme a Figura 3 ,

Durante a tarde, marcamos também os raios de sombra de mesmo tamanho $s_{4}$ e $s_{2}$ 


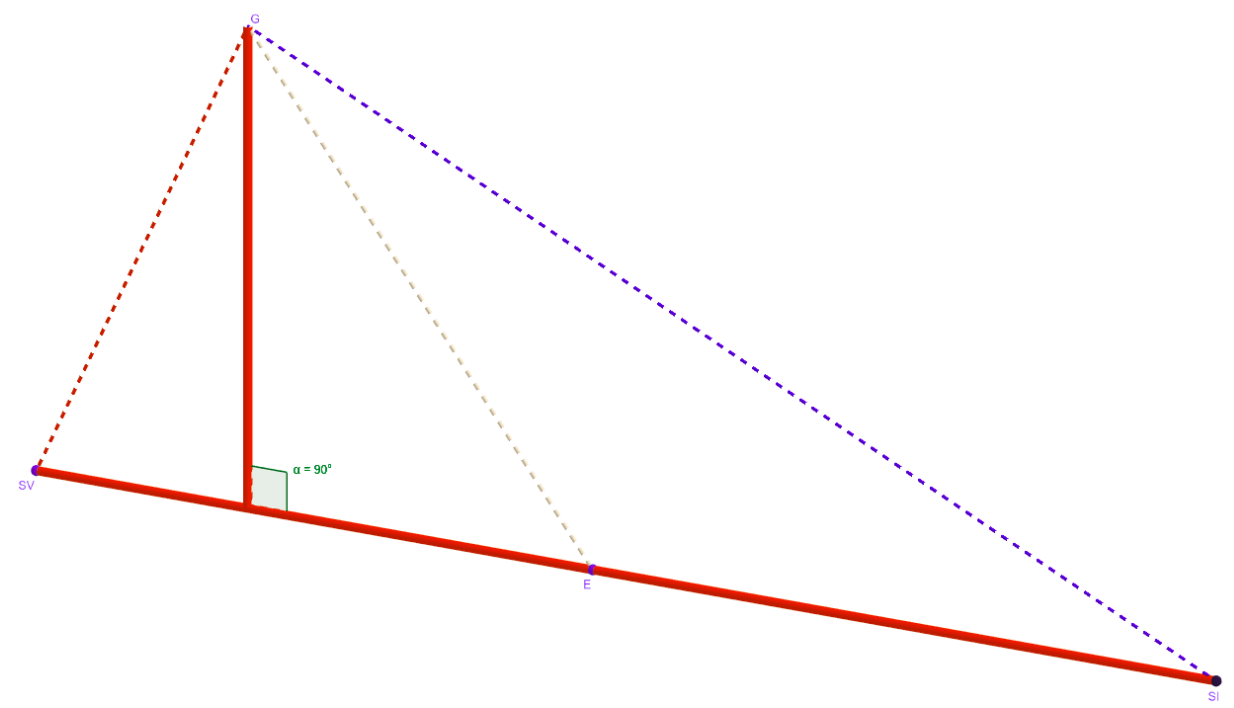

Figura 2: Sombra mínima de um gnômon nos solstícios de verão (SV), equinócios (E) e solstícios de inverno (SI) numa região tropical. Fonte: Arquivo pessoal do autor.

respectivamente, projetados pelo gnômon que atingem a extremidade de cada um dos arcos de circunferências feitos no período da manhã, de modo a obter vários ângulos com vértices no pé do gnomon, cujos lados são os pares de raios de um arco de uma mesma circunferência de sombra. Traçamos as bissetrizes de cada par desses raios de sombras congruentes. Elas coincidem? Evidentemente que sim. A bissetriz comum destes ângulos de sombra de mesmo tamanho é a linha meridiana do local, indicando a direção $\mathrm{N}$ - S, e é o eixo de simetria dos raios de sombra de mesmo tamanho.

É importante em cada etapa do experimento propormos a discussão dos conceitos de perpendicularismo e do plano do horizonte ao fincar o gnômon no solo, bem como questionarmos problemas relacionados, por exemplo, como os operários das construções prumam os muros e paredes, como fazem as medições, cálculos e como eles orientam as construções de modo a otimizar a energia solar recebida durante o dia.

Explorando o perpendicularismo entre a linha meridiana, obtemos a linha L - O, obtendo os pontos cardeais a partir do meridiano local. Com as linhas $\mathrm{N}-\mathrm{S}$ e L - O podemos construir uma Rosa dos Ventos, conforme a Figura 4 a seguir.

Tomando-se a direção das bissetrizes dos pontos cardeais, N - S - L - O, obtém-se os 4 pontos colaterais localizados entre os quatro pontos cardeais: Nordeste (NE), No- 


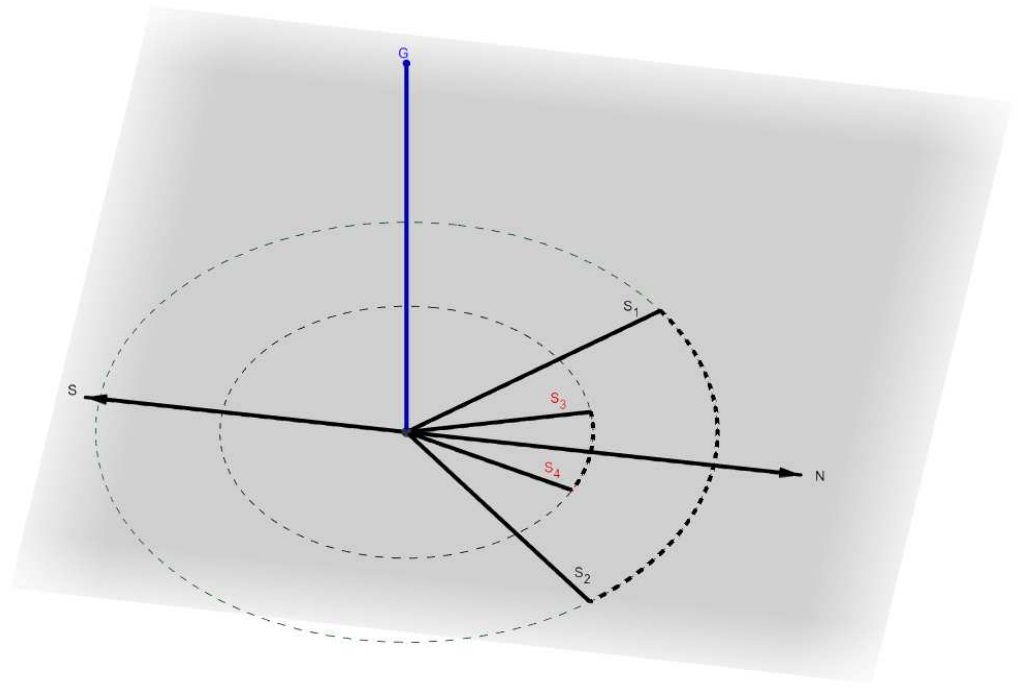

Figura 3: Arcos e raios de sombra de mesmo tamanho, bissetriz e linha meridiana. Fonte: Arquivo pessoal do autor.

roeste (NO), Sudeste (SE) e Sudoeste (SO). Do mesmo modo, as bissetrizes dos pontos colaterais geram os 8 pontos subcolaterais, localizados entre um ponto cardeal e um ponto colateral, Norte - nordeste (NNE); Norte - noroeste (NNO); Leste - nordeste (ENE); Leste - sudeste (ESSE); Sul - sudeste (SSE); Sul - sudoeste (SSO); Oeste - sudoeste (OSO) e Oeste - noroeste (ONO). Em seguida, obtém-se os 16 pontos intermediários, bissetrizes localizadas entre dois pontos obtidos anteriormente (cardeal e colateral ou subcolateral), chamados de intermediário entre S e SSE; intermediário entre NE e NNE, etc. Observamos uma progressão geométrica dos números de direções à medida que vamos traçando tais bissetrizes entre os pontos indicados em cada etapa.

Muitas civilizações construíram templos que serviram para marcação do tempo e realização de cultos religiosos e adorações em suas vilas, seguindo uma orientação especial de acordo com a localização e movimento aparente dos astros. Evidências aparecem nos sítios arqueológicos das várias partes do mundo como Almendres (Portugal), Carnac (França), Pirâmides (Egito), Stonehenge (Inglaterra) e os dos impérios Astecas, Incas, Maias, etc. Na mesoamérica pré-colombiana FIERRO [8] cita que existiam calendários astronômico de 365 dias, dividido em 18 meses de 20 dias cada e um relacionado com o 


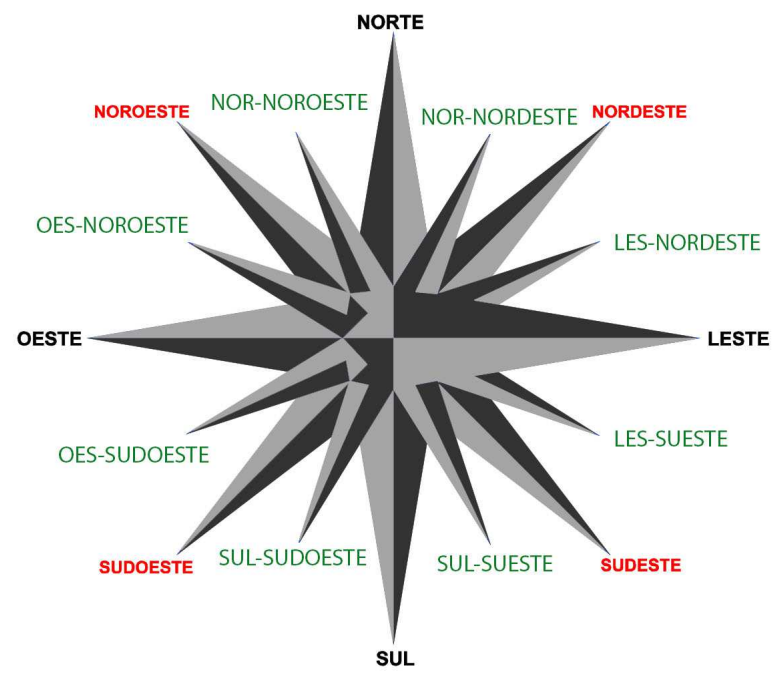

Figura 4: Rosa dos ventos. Fonte: Arquivo pessoal do autor.

período de translação de vênus de 260 dias usado para as festas religiosas.

Na Seção 5 apresentamos um convite para exploração de vários problemas desse tipo como projetos interdisciplinares.

\section{Sombra e medidas de objetos inacessíveis}

Quando Tales de Mileto ( $\approx 625$ a.C. - $\approx 546$ a.C.) visitou o Egito no século VI a.C. conta-se que ele calculou a altura da Grande Pirâmide, orientada precisamente para os pontos cardeais.

Conforme BOYER [4], conjectura-se ter sido ele o criador da geometria demonstrativa. Por isto, ele é saudado como o primeiro matemático a dar uma contribuição à organização da geometria. Além disso, ele deixou-nos uma técnica simples para medir alturas e distâncias de objetos inacessíveis, provavelmente usando o fato dos raios solares chegarem paralelos a Terra e a semelhança de triângulos retângulos de acordo com HOGBEN [7] e BOYER [4].

Provavelmente, fincou um gnômon de altura $h$ e desenhou no chão uma circunferência com raio $r$ igual a sua altura e, no momento em que a sombra atingia a circunferência, a sombra da pirâmide $R$ também ficava igual à altura dela $H$. Com isso, estabelecia uma das primeiras aplicações do triângulo isósceles e da semelhança de triângulos conforme a Figura 5. Utilizando as ideias de Tales pode-se propor aos estudantes o cálculo da altura 


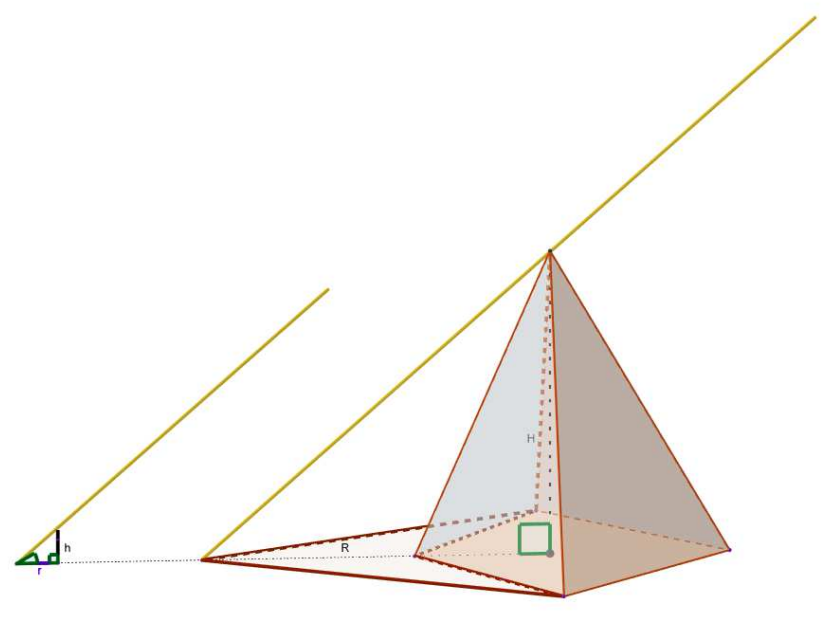

Figura 5: Comparando sombras de um gnômon e de uma Pirâmide para medir sua altura. Fonte: Arquivo pessoal do autor.

do prédio da escola, da torre da igreja, do portal da cidade ou de um objeto inacessível. E questionar, quando a sombra do gnômon não for igual ao tamanho dele, ainda podemos calcular a altura da pirâmide utilizando semelhança de triângulos?

Outra grande proeza realizada no século III a.C. foi quando Eratóstenes de Cirene (276 a.C. - 194 a.C.), considerou três hipóteses fundamentais para calcular a medida da circunferência da Terra (cerca de $40000 \mathrm{~km}$ ) e se consagrou como um dos primeiros modelos matemáticos de problemas inversos:

1. Que a Terra era esférica;

2. Que o sol era muito maior do que a Terra e estava muito distante, de modo que os raios solares chegassem paralelos aqui;

3. E que as cidades de Alexandria e Siena (atual Assuã) do Egito estavam num mesmo meridiano terrestre, conforme esquema da Figura 6. Ele calculou o comprimento da circunferência da Terra, utilizando as propriedades da circunferência e dos ângulos alternos internos de duas retas paralelas (raios de Sol) cortadas por uma transversal e uma simples regra de três. Com a suposição de que a diferença entre os ângulos $\alpha$ de sombras dos raios solares em Alexandria e Siena, quando projetados simultaneamente nos dois locais sobre um mesmo meridiano, está para a distância $d$ que os separa, assim como o ângulo 


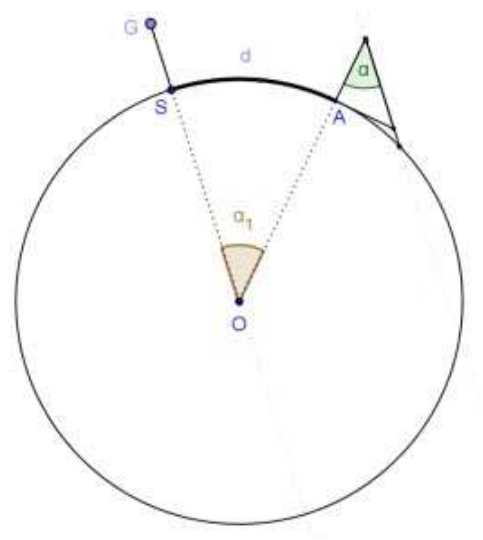

Figura 6: Esquema de Eratóstenes. Fonte: Arquivo pessoal do autor.

da circunferência da Terra, $360^{\circ}$, está para todo o comprimento $C$ dela, ou seja:

$$
\frac{\alpha}{d}=\frac{360^{\circ}}{C} \quad \Longleftrightarrow C=360^{\circ} \frac{d}{\alpha} .
$$

Verifique num globo terrestre se a cidade de Assuã, antiga Siena, e a cidade de Alexandria, no Egito, usadas por Eratóstenes no século III a.C. para medir a circunferência da Terra, estão sobre um mesmo meridiano. Observe que uma linha N - S sobre um globo é uma geodésica, semicircunferência máxima da Terra chamada meridiana.

$\mathrm{Na}$ Seção 5 propomos algumas experiências relacionadas como a de Eratóstenes.

\section{Relógio solar}

A marcação do tempo e a história do relógio de sol pode ter começado com o ritimo do dia e noite que regulava a vida dos povos primitivos por milhões de anos conforme ROHR [10]. O gnômon é um relógio de sol vertical mais simples que foi muito usado pelas primeiras civilizações, como o desenhado na Figura 7 por um estudante do ensino fundamental I.

Em muitas cidades existem obeliscos para enfeitar suas praças, jardins ou instituições, provavelmente herdados do simples gnômon, usado para marcar as horas do dia, início das estações do ano, etc. localizado no centro das aldeias ou vilas das primeiras civilizações.

A observação da altura do sol em relação ao horizonte ainda é usada por muitas comunidades interioranas para estimar as horas. E a observação do tamanho e da direção 


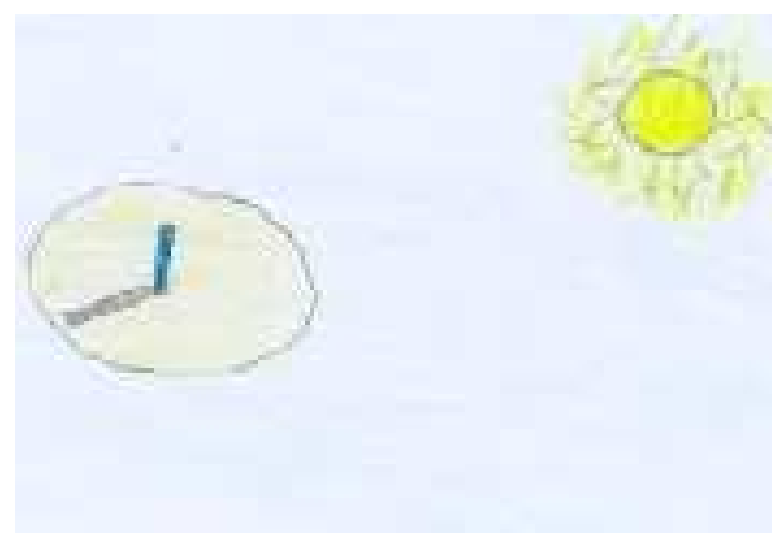

Figura 7: Gnômon e tamanho de sombra. Fonte: Arquivo pessoal do autor.

da sombra de um gnômon nas várias épocas do ano ainda é utilizada por tribos indígenas brasileiras para orientação de suas aldeias e marcação do tempo conforme AFONSO [1] e SCANDIUZZI [11], mesmo nos dias de hoje, com as novas tecnologias.

Conhecendo-se a linha meridiana e a latitude do local (que é o ângulo entre o equador terrestre e o paralelo do lugar ou a altura do polo celeste elevado), podemos construir os mais simples relógios solares como o de mostrador equatorial e de mostrador horizontal conforme BOCZKO [3].

\subsection{Relógio solar com montagem equatorial}

Para construir um relógio de sol com montagem equatorial podemos usar materiais simples. Basta um semidisco de isopor, papelão, madeira, transferidor, etc. com marcações igualmente espaçadas para as horas e uma vareta para o gnômon.

A ideia é apontar um gnômon para o polo celeste elevado do local, como se fosse o eixo no qual o mundo aparentemente gira $360^{\circ}$ em 24 horas. Supondo o movimento de rotação da Terra uniforme durante o dia, graduamos um semidisco invertido em relação a esfera celeste, ortogonal ao gnômon e paralelo ao equador, das 6 às 18 horas, de hora em hora, com intervalos igualmente espaçados de $15^{\circ}$ pois, por uma simples regra de três, vemos que a cada rotação da Terra de $15^{\circ}$ corresponde a 1 hora (um fuso horário).

O semidisco centrado no eixo (gnômon), como se a concavidade da esfera celeste fosse invertida num plano perpendicular ao gnômon (apontado para o polo elevado), pode ser fixado numa placa, inclinada de um ângulo de $90^{\circ}-\phi$ com a horizontal, em que $\phi$ é a latitude local, conforme Figura 8, O eixo da esfera celeste, prolongamento do eixo terrestre, funciona como um grande ponteiro fixo para determinação das horas. 


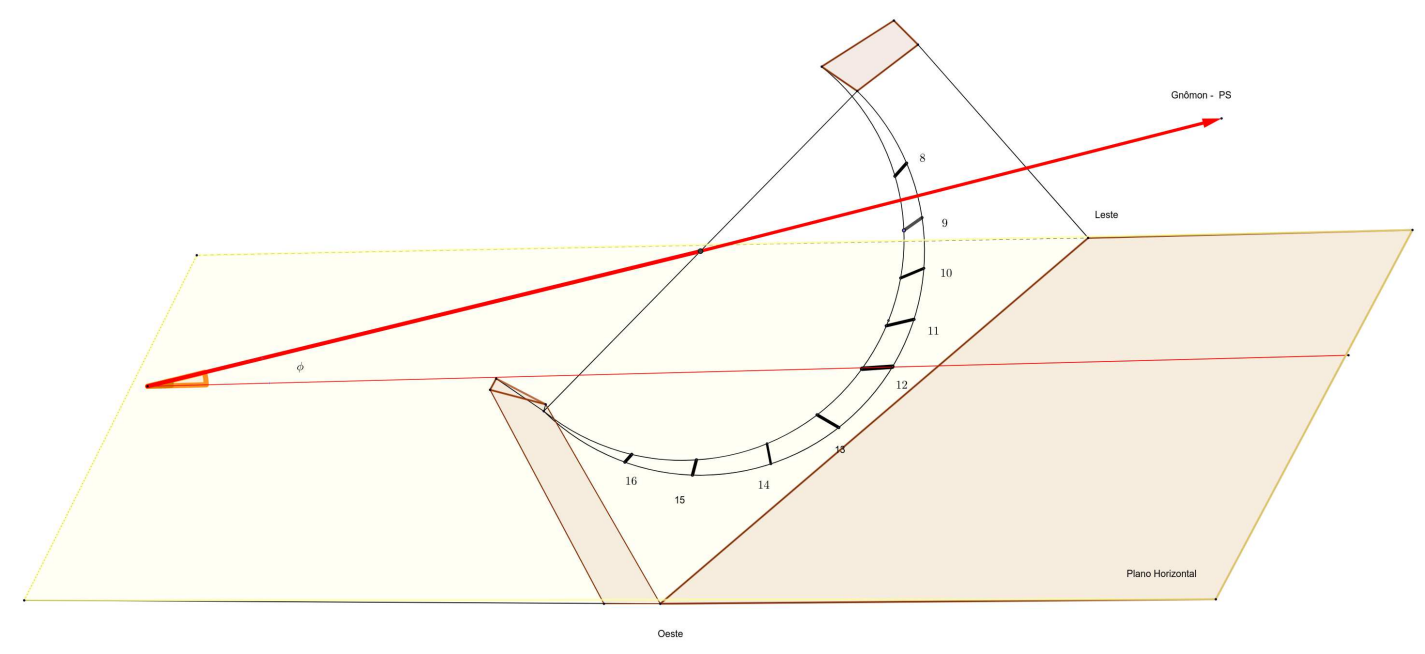

Figura 8: Relógio de sol com montagem equatorial. Fonte: Arquivo pessoal do autor.

Uma observação importante é que o relógio de sol é específico para cada local, pois depende da latitude do lugar.

\subsection{Relógio solar com montagem horizontal}

Outro tipo de relógio solar simples é o de mostrador horizontal como na Figura 9.

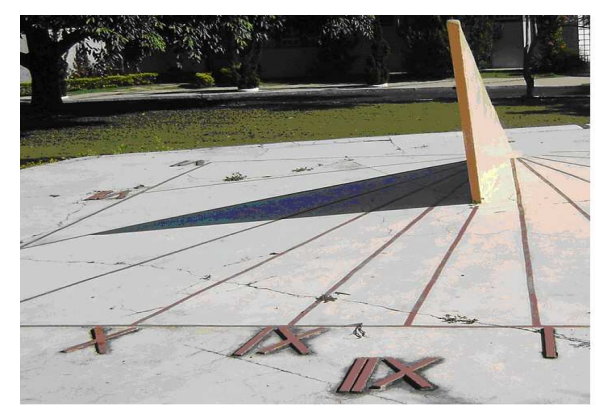

Figura 9: Relógio de sol com mostrador horizontal em Águas de São Pedro - SP. Fonte: Arquivo pessoal do autor.

Composto também de um gnômon com ângulo de inclinação da latitude local, apon- 
tando para o polo celeste elevado ele projeta a sombra das horas no plano do horizonte local. Os valores dos ângulos $\theta$ correspondentes a cada hora do ângulo horário do Sol na montagem equatorial projetados no plano do horizonte podem ser calculados utilizando trigonometria.

Para determinar os ângulos horizontais das horas inteiras podemos utilizar uma figura auxiliar constituída por um tetraedro POQR, conforme a Figura 10 com três ângulos retos comparamos as relações trigonométricas de suas faces constituídas dos triângulos retângulos $\triangle P O Q, \triangle P Q R$ e $\triangle O Q R$. O tetraedro pode ser feito de papelão e planificado para melhor entendimento das relações trigonométricas de suas faces.

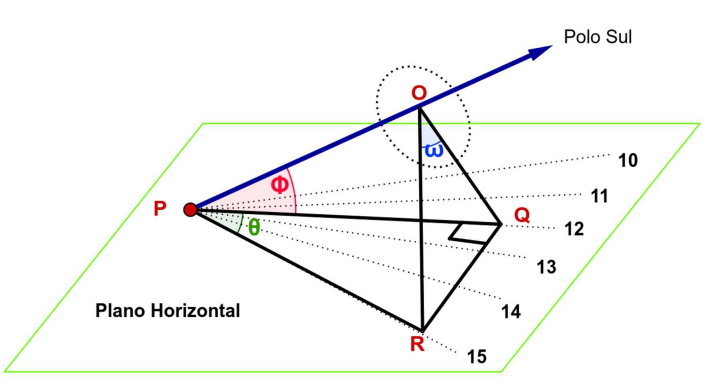

Figura 10: Montagem horizontal de um relógio de sol. Fonte: Arquivo pessoal do autor.

De fato, na Figura 10, observamos que o triângulo $\triangle P O Q$ é retângulo em $\mathrm{O}$, e verificamos as seguintes relações trigonométricas:

$$
\operatorname{sen} \Phi=\frac{O Q}{P Q} ; \quad \cos \Phi=\frac{O P}{P Q}, \quad \text { e } \quad \tan \Phi=\frac{O Q}{O P} .
$$

em que $Q P, P Q$, etc. são as respectivas medidas das arestas $Q P, P Q$, etc. do tetraedro considerado. Da primeira e terceira relações da Equação (1), escrevemos;

$$
O Q=P Q \operatorname{sen} \Phi \text { e } O Q=O P \tan \Phi
$$

Nos outros triângulos, faces do tetraedro, também podemos explorar as relações trigonométricas. O triângulo $\triangle P Q R$ retângulo em Q nos dá a tangente da abertura horizontal $\theta$

$$
\tan \theta=\frac{Q R}{P Q}
$$


Do triângulo $\triangle O Q R$, retângulo em Q, escrevemos a tangente do ângulo $\omega$ de abertura circular superior da Figura 10, como

$$
\tan \omega=\frac{Q R}{O Q}
$$

Ao multiplicarmos e dividirmos o segundo membro da Equação (3) pelo tamanho do segmento $\mathrm{OQ}$, rearranjando e escrevendo a tangente do ângulo $\theta$ de abertura no plano horizontal com relação à sombra do meio - dia temos

$$
\tan \theta=\frac{Q R}{P Q}=\frac{Q R}{O Q} \frac{O Q}{P Q}
$$

Usando a expressão para $\tan \omega$ da Equação (4) e $\operatorname{sen} \Phi$ da Equação (1) na expressão anterior (5), obtemos

$$
\tan \theta=\tan \omega \operatorname{sen} \Phi
$$

Portanto, o ângulo $\theta$ de sombra no plano do horizonte em relação a linha meridiana pode ser dado em função do ângulo $\omega$, correspondente as horas na montagem equatorial, e da latitude local $\Phi$,

$$
\theta=\arctan (\tan \omega \operatorname{sen} \Phi) \text {. }
$$

Para cada ângulo do tipo $\omega=15 n, n=6,5,4,3,2,1,0,-1,-2,-2,-4,-5,-6$ temos os ângulos das horas contadas a partir de $n=0$ correspondente a $\omega=0$ na montagem horizontal. O ângulo de zero grau, $\theta=0^{\circ}$, a projeção da sombra está sobre a linha meridiana local, marcando às 12 horas, ou meio - dia verdadeiro local.

Quando a sombra do gnômon estiver sobre cada uma das posições graduadas das horas inteiras, podemos ver a sequência de valores da hora solar verdadeira local, desde 6 horas da manhã às 6 horas da tarde de acordo com o ângulo

$$
\theta=\arctan (\tan 15 n \operatorname{sen} \Phi)
$$

a partir da linha meridiana

Por exemplo, para um ponto da superfície terrestre situado na UFSCar, com Latitude (Sul) 21 graus e 58 minutos (LatitudeDM-UFSCar $=21,96^{\circ}$ ) conforme SALVADOR [12], o cálculo dos ângulos de sombra das horas no plano horizontal formados com a direção do meridiano (meio - dia verdadeiro) pode ser feito com uma calculadora ou numa planilha no computador, integrando com as tecnologias, obtendo as horas da manhã:

$$
\theta_{12}=0^{o}, \theta_{11}=5,7^{o}, \theta_{10}=12,2^{o}, \theta_{9}=20,5^{\circ}, \theta_{8}=32,9^{\circ}, \theta_{7}=54,4^{o}, \theta_{6}=90^{\circ}
$$


e, devido à simetria temos os mesmos ângulos para o período da tarde:

$$
\theta_{13}=5,7^{\circ}, \theta_{14}=12,2^{\circ}, \theta_{15}=20,5^{\circ}, \theta_{16}=32,9, \theta_{17}=54,4^{o}, \theta_{18}=90^{\circ} .
$$

Para $\omega=15 \times 2=30$ graus, a partir da linha meridiana correspondente às 10 horas local, $\theta_{10} \approx 12,2$, e devido à simetria, às 14 horas temos o mesmo ângulo de sombra $\theta_{14}$ do outro lado do meridiano.

Na construção descrita não levamos em conta os efeitos que podem ser representados matematicamente pela equação do tempo, que estabelece a diferença entre o tempo solar verdadeiro e o tempo solar médio. A justificativa é dada pela inclinação do eixo terrestre em relação a eclítica, plano de sua órbita, pois o movimento aparente do Sol ocorre ao longo da eclíptica, e não no plano do equador celeste, além da velocidade orbital variável, pois a trajetória da Terra ao redor do Sol é uma curva elíptica com o Sol ocupando um dos seus focos (embora nem tanto excêntrica como geralmente aparece nas ilustrações) e não circular como se acreditava antes do astrônomo alemão Kepler (1571 - 1630) estabelecer as leis planetárias conforme OLIVEIRA FILHO \& SARAIVA [9].

Para ter uma atividade contínua ao longo do ano, propomos a construção de um relógio de sol na escola e um analema, um gráfico e/ou tabela indicando a diferença da hora do relógio solar verdadeira observada nas várias épocas do ano (dias, semanas, meses, ano) com a hora solar média (tempo civil) obtendo experimentalmente as devidas correções.

\section{Algumas sugestões de projetos interdisciplionares}

Conforme vimos, vários temas interdisciplinares, relacionados com as disciplinas do ensino básico e astronomia, podem contribuir para o aprendizado de conceitos matemáticos e de ciências conforme prega a BNCC [2]. Citamos alguns exemplos que poderão ser completados e mais explorados com turmas de estudantes do ensino básico, inclusive incorporando as tecnologias para pesquisa e elaboração de planilhas, gráficos e cálculos.

Nas atividades propostas aos docentes envolvidos nos projetos interdisciplinares sugerimos que inicialmente sejam promovidas discussões e sejam elaboradas com antecedência Fichas de Atividades com as questões a serem exploradas pelos estudantes. Sugerimos ainda que, cada observação e/ou experimento contenha um cabeçalho com dados tipo: Nome da escola; título da atividade; nomes dos estudantes do grupo; ano e período escolar (conveniente para o experimento); professores responsáveis; Localidade (Cidade, Estado, País); Latitude local; Longitude local; Altitude, Data e Hora Local; objetivos da atividade: descrição das competências e habilidades específicas de acordo com a BNCC; metodologias a serem utilizadas no desenvolvimento do projeto. 
É importante ressaltar que as atividades propostas não são específicas para algum período da educação, podendo ser adequadas para aplicação a estudantes de diversos períodos, cabendo ao professor o conveniente ajuste ao currículo e a elaboração de estratégias didático-metodológicas viáveis.

1. Observar o sol num dia, semana, mês, semestre ou durante o ano:

i. Anotar: horário do nascer e do pôr do sol; horários da observação; tamanhos e as direções das sombras de um gnômon vertical ou de um objeto fixo (como torre de igreja, parede de um prédio ou da escola) nas várias horas do dia.

ii. Determinar qual é o tamanho da sombra mínima durante um dia, uma semana, um mês e ao longo do ano.

iii. Explorar a curva obtida ao ligarmos as marcas da ponta da sombra do gnômon vertical durante os dias dos experimentos.

iv. Elaboração e análise de uma planilha com tabelas e gráficos com o software GeoGebra [5], por exemplo.

2. Determinar o meridiano local para fazer uma rosa dos ventos colorida na escola, praça ou jardim.

Pode-se integrar com atividades envolvendo outras ciências. Pode-se, por exemplo, plantar flores ou folhas de cores ou tonalidades diferentes em cada direção. As letras N, S, L e O podem ser marcadas com plantas ou por garrafas tipo pet, contendo água clorada colorida (cuidado que pode manchar a roupa) enterradas pela metade e bem fixadas no solo. Sugerimos sempre o respeito à sustentabilidade com a redução dos gastos, reutilização e reciclagem de materiais, usando sempre que possível, sucatas para desenvolver kits adequados às várias atividades educacionais. Pode-se ainda, Conhecendo-se os pontos cardeais, enfocar o problema da direção com desafios matemáticos. Pode-se explorar a direção da frente da escola ou da casa de cada estudante, de cada estado, país, etc. e inclusive com brincadeiras de desafios como caça ao tesouro com os estudantes das primeiras séries.

3. Projeto de construção de um gnômom vertical e um relógio de sol.

Pode ser de papelão, de madeira, garrafa pet cilíndrica reta transparente, ou com materiais de construção no próprio pátio da escola que faz parte do ambiente de aprendizagem e socialização. O gnômom construído pode ser utilizado para observar a hora solar verdadeira e anotar a diferença da hora civil durante um período ou ano. 
4. Reprodução da experiência de Eratóstenes para determinar o tamanho de uma esfera de isopor.

i. Prender dois estiletes (gnômons) perpendiculares a superfície esférica, alinhálos sobre o meridiano local. Se nenhum deles ficar na direção dos raios solares ao meio - dia solar verdadeiro, verificar, usando uma regra de três simples, que a diferença dos ângulos de sombra dos estiletes está para a distância entre eles, assim como $360^{\circ}$ está para o comprimento da circunferência máxima da esfera inteira.

ii. Pesquisar outras maneiras de determinar o raio da Terra, como por exemplo utilizar o software Google Earth [6] ou um mapa para determinar a distância entre duas cidades de latitudes diferentes sobre um mesmo meridiano para calcular a medida da Terra. Considerar, por exemplo, dois locais A e B na superfície terrestre a uma distância $d$ e com a mesma longitude e com latitudes distintas $\phi_{1}$ e $\phi_{2}$, respectivamente. Mostrar que o raio $r_{T}$ da Terra pode ser obtido por $r_{T}=\frac{180 d}{\pi\left(\phi_{2}-\phi_{1}\right)}$.

5. Explorar o globo terrestre e as coordenadas geográficas para entender os conceitos de latitude, longitude, meridianos e paralelos. Estudar as relações entre o meridiano referencial de Greenwich e os fusos horários nos estados do Brasil e nas várias partes do mundo, observando a diferença das horas em cada um dos locais.

Sugere-se localizar outras escolas ou locais que estão sobre o mesmo meridiano e discutir os resultados de observações e experiências sobre as posições do sol durante vários horários de um mesmo dia, a altura máxima do Sol e, consequentemente, sombra mínima de um gnômon, etc. e compará-los. Observar a duração dos dias mais longos do verão e discutir as vantagens e desvantagens de estabelecer o horário de verão em alguns países.

6. Pesquisar as coordenadas cartesianas planas, as coordenadas esféricas e as coordenadas geográficas, coordenadas celestes (horizontal e equatorial). Imaginar e pesquisar como devem ser as coordenadas celestes: ascensão reta e declinação dos astros.

7. Pesquisar, construir e testar instrumentos de medida como: astrolábio, teodolito, bússola, sextante e outros que foram usados desde as grandes navegações antes mesmo da descoberta do Brasil. Explorar os instrumentos usados hoje com as novas tecnologias. Explorar a notação científica para os números marcados pelos instrumentos ou calculados. 
8. Pesquisar e comparar as distâncias dos planetas ao Sol e seus tamanhos. Elaborar maquetes em escalas para as distâncias e tamanhos de modo que possam ser representados em certos locais, pontos da escola ou da sua cidade.

9. Pesquisar sobre os monumentos antigos, como as pirâmides do Egito, o de Stonehenge no sul da Grã-Bretanha, que provavelmente serviu de observatório astronômico ou para cultos religiosos e de orientação para os povos que viveram na região há milênios. Pesquisar letras de músicas, poesias, romances, peças teatrais, filosofia, etc. que contenham tópicos que citem ou explorem os astros (sol, lua, estrela, etc.) ou que demonstrem como os autores descreviam o mundo, como Dante, no século XIII, em sua obra Divina Comédia ou noutras famosas obras literárias medievais de pensadores, poetas e antigos historiadores.

10. Exploração da luz do sol e a importância dos fenômenos relacionados com a vida, tais como os processos de fotossíntese, a decomposição da luz, o arco - íris (ou duplo arco - íris), a composição química do sol, as reações nucleares que ocorrem no interior do sol ou de uma estrela, etc. Pode-se realizar experiências com uma lanterna e um globo terrestre (ou bola de isopor) para compreender a iluminação dos hemisférios terrestre nas várias estações do ano. Pode-se ainda orientar os alunos a pesquisarem a orientação, iluminação e a ventilação natural de suas casas, de suas escolas, locais de trabalho ou de estudo.

11. Simulação de um planetário.

Utilizar o software stellarium [13] ou Celestia [14] para estimular os alunos a explorar o céu do lugar onde ele mora, os planetas, constelações e suas características. Como ele veria outras constelações no céu se morasse noutro hemisfério. Quão brilhantes e distantes estão as estrelas das constelações mais conhecidas do zodíaco.

12. Pesquisar e discutir sobre como Aristarco de Samos (310 a.C. - 230 a.C), um dos primeiros heliocentristas, ou outros pensadores antigos calcularam as distâncias e os diâmetros do Sol, da Lua, etc. utilizando argumentos geométricos e trigonometria.

A integração dessas atividades e outras relacionadas com as várias disciplinas e com outras escolas poderão enriquecer a abordagem, aprendizagem e a socialização.

\section{Considerações finais}

Este trabalho vislumbra a possibilidade dos Professores despertarem em seus estudantes as ciências e matemática, considerando o maior laboratório natural que é o mundo que 
vivemos.

A proposta de observação dos fenômenos diários, como o movimento aparente e caminho dos astros, descrevendo arcos num plano ortogonal ao eixo terrestre e suas consequências, traz para as escolas em que se tem bastante espaço ao ar livre ou em pesquisas de campo, acantonamento no interior, etc. as vantagens da interdisciplinaridade e contempla as propostas da Base Nacional Comum Curricular para o Ensino Básico tais como o desenvolvimento do raciocínio lógico, o espírito de investigação e a capacidade de discutir e produzir argumentos convincentes, recorrendo aos conhecimentos matemáticos para compreender e atuar de forma crítica e construtiva no mundo de hoje. Tais atividades divulgadas em eventos científicos e no nosso programa de Educação Continuada fazem com que os Professores participantes se tornem multiplicadores em suas escolas o que é muito gratificante para nós docentes e para os estudantes.

\section{Referências}

[1] AFONSO, G. Mitos e estações no céu tupi - guarani, Scientific American Brasil, $38-47, N^{\circ} 45,2006$.

[2] BRASIL. Base Nacional Comum Curricular (BNCC). Educação é a Base. Brasília, MEC/CONSED/UNDIME, 2017. Disponível em: http:// basenacionalcomum.mec.gov.br/abase. Acesso em: 20 mar. 2020.

[3] BOCZKO, R. Conceitos de Astronomia, São Paulo, Edgard Blucher, 1998.

[4] BOYER, C. B. História da Matemática, trad. Elza. F. Gomide, São Paulo, Edgard Blucher, 1996.

[5] GEOGEBRA. Geogebra.org. Diponível em: https://www.geogebra. org/ . Acesso em: 02 mar. 2020.

[6] O GLOBO terrestre mais detalhado do mundo. Google earth. Diponível em: https://www.google.com/earth/. Acesso em: 05 abr. 2020.

[7] HOGBEN, L. Maravilhas da Matemática, trad. P. M. da Silva, Porto Alegre, Globo, 1958.

[8] FIERRO, J. La astronomia del México, México, Lectorum, 2001.

[9] OLIVEIRA FILHO, K. S. e SARAIVA, M. de F. O. Astronomia e Astrofísica, $2^{a}$ ed., São Paulo, Livraria da Física, 2004. 
[10] ROHR, R. R. J. Sundials, History, Theory and practice, Dover, 1970.

[11] SCANDIUZZI, P. P. Educação Indígena x Educação Escolar Indígena: Uma Relação Etnocida em uma Pesquisa Etnomatemática, Tese de Doutorado, UNESP, Marília, 2000.

[12] Salvador, J. A. Ciências e Matemática do Sol e do Gnômon, Anais IV SEMAP, UFU, Ituiutaba, 2013. Disponível em https://drive.google. com/file/d/0B7wGfu8ohzQSN1ZESHNaa3hYZ2s/edit?pli=1. Acesso em: 20 mar. 2020.

[13] STELLARIUM. Stellarium.org. Diponível em: https: / / stellarium.org/ pt / . Acesso em: 06 abr. 2020.

[14] SOURCEFORGE. Celestia. Diponível em: https://sourceforge.net/ projects/celestia/. Acesso em: 04 abr. 2020.

Submetido em 11 abr. 2020

Aceito em 12 jun. 2020 